\title{
Private education and disadvantage: the experiences of assisted place holders
}

\author{
Sally Power, School of Social Sciences, Cardiff University \\ Andrew Curtis, Community Development Foundation \\ Geoff Whitty, Institute of Education, University of London \\ Tony Edwards, University of Newcastle
}

\begin{abstract}
It is now nearly thirty years since Margaret Thatcher and her Conservative administration introduced the Assisted Places Scheme (their first education policy) and over ten years since New Labour abolished it. The Scheme, which was designed to provide a ladder of opportunity for academically able students from poor backgrounds to attend private schools, is of more than historical interest. It can be used to illuminate enduring sociological concerns about the relationship between home and school. This paper draws on retrospective interview data to reveal how the Scheme was experienced by its more disadvantaged beneficiaries. Revisiting classic sociological analyses from the 1960 s and 1970s, it unravels the complex interactions between home background, friendship networks and school cultures and shows how these contributed to contrasting experiences of commitment, detachment, estrangement and alienation. These differing modes of engagement with schooling appear to have had lasting effects on our respondents and influenced their subsequent careers and orientations.
\end{abstract}

Keywords: assisted places scheme; private schools; pupil engagement; school culture; Bernstein. 


\section{Private education and disadvantage: the experiences of assisted place holders}

It is now nearly thirty years since Margaret Thatcher and her Conservative administration introduced the Assisted Places (AP) Scheme in England and Wales. It was their first education policy. Eighteen years later, and as their first education policy, New Labour abolished it. The Scheme was designed to provide a 'ladder of opportunity' for academically able students from poor backgrounds. Between 1981 and 1997, over 75,000 pupils received means-tested assistance from public funds to attend some of the country's most selective and prestigious private schools. The Scheme remained controversial throughout its lifetime and was subjected to a variety of critiques. Some argued that it damaged the public sector because it 'creamed off' academically able students from state schools and sent out a clear signal that private schools were better (see Walford 1987). Other criticisms focused on the extent to which it was subsidising the already advantaged because research (Douse 1985; Edwards et al 1989) showed that only a minority of beneficiaries came from socio-economically disadvantaged or minority ethnic backgrounds.

These criticisms may be countered by arguing that its impact should be measured in terms of the educational opportunities it provided for the 'deserving' few who did participate in the Scheme. However, even by this criterion, the Scheme does not appear to have been an unqualified success. As part of our ongoing investigations of education and the middle class (Power et al 2003; 2006a), we have been following the progress of a cohort of academically able young men and women since the early 1980s. Of this cohort, 157 received an assisted place. Recent quantitative analysis of the relative performance of 
AP holders (Power et al 2006b) shows that, while the Scheme did provide some students with a pathway to high level qualifications, elite university places and occupational success, others were unable or unwilling to take advantage of the opportunities offered by their private education. Students from working class and manual backgrounds in particular appeared to have done less well than their counterparts in state schools.

In trying to unravel this variable pattern of success and failure, we were funded by the Sutton Trust to undertake further research on 25 of the most disadvantaged AP holders from the cohort to see where we could identify factors which might account for their differential progress.

\section{Methods}

Because the Scheme was often colonised by more advantaged students, it was difficult to find many with unambiguously working class backgrounds among the 157 AP holders in the original cohort. Indeed, we were only able to identify and make contact with ten who had come from working class homes. We therefore broadened our definition of 'disadvantage' to include eight children who came from 'intermediate' backgrounds, for example whose parents held secretarial or non-manual supervisory positions. Although that might seem too loose a definition of disadvantage, this group of parents is often overlooked within sociological analyses which usually employ a crude middle/working class division. Certainly, within the socially and financially privileged milieux of our elite schools, 'intermediate' status would be experienced as at the lower end of the occupational hierarchy. Additionally, and in order to bring a different dimension to 
'disadvantage', we included in our sample those pupils who came from homes which were impoverished through parental death, divorce or unemployment. Twelve of our 25 respondents (17 men and 8 women) came from single-parent families. The overall socioeconomic background of our sample is indicated below.

\section{TABLE 1 GOES ABOUT HERE}

There was, for the most part, a very close relationship between parents' occupational category and level of educational inheritance. There was also a strong relationship between occupational category and single parent status. Those with higher level occupations and higher level qualifications tended to come from single parent families which of course is one of the factors behind their having been eligible for financial assistance. Those with working class and intermediate occupations and low levels of education tended to come from two-parent households.

Semi-structured interviews were conducted in person or over the phone. The interviews usually took at least forty minutes and sometimes considerably longer as respondents recalled their time at school. Clearly, data derived from asking the respondents to reflect back to a period of over twenty years ago will have particular limitations. Reminiscences

are inevitably partial and selective. However, it is possible that the passage of time has provided respondents with a clearer sense of the legacy of their schooling.

\section{The analytical framework}

One of the pleasures of this research was revisiting early studies within the sociology of education which seemed to have particular relevance. For example, Jackson and 
Marsden's (1966) Education and the Working Class provides the model for combining an awareness of the social structure with sensitivity to cultural allegiances. King's (1969) Values and Involvement in a Grammar School offers an important parallel in that it explores the complex connection between the culture of the family and the culture of the school. There is also a strong resemblance between the culture of the grammar school of the 1960s and the selective independent schools that we researched in the 1980s. Finally, and like King, we draw on Bernstein's (1977) Sources of Consensus and Disaffection in Education for an analytical framework for categorising and explaining different modes of engagement between pupil and school. ${ }^{1}$

Bernstein (1977, elaborated by King 1969) argues that the sources of consensus and disaffection in education may be understood through exploring the relationship between the culture of the school and the orientation of the family to that culture. The pupil's involvement in the school is influenced by four important factors:

The pupil's family: Is there continuity between the values of the home and the values of the school?,

The social structure of the school: What is obligatory, what is voluntary? How are the expressive (social) and instrumental (academic) dimensions of the school organised?

Peer group relations: Are these culturally-continuous or -discontinuous with the school? Are neighbourhood or school friendships more important?

\footnotetext{
${ }^{1}$ See Power et al (1998b) for the application of this framework to compare pupil involvement at a private selective and state comprehensive school.
} 
Perceived future: Does the pupil sees the school as providing the route to a desired occupation/higher education?

As Bernstein argues, involvement is multifaceted. There is no simple continuum between high and low levels. Moreover, levels and mode of involvement may change over time. The level and kind of involvement depend on whether the pupil understands, accepts and can realise the means and ends of the social and academic dimensions. Drawing on Merton's framework for analysing suicide, Bernstein identifies a range of possible relations (Table 2) that the family may have with the school.

\section{TABLE TWO GOES ABOUT HERE}

Commitment is the strongest form of involvement, where the pupil understands the means and accepts and can realise the ends of the academic and the social dimensions of the school. Detachment involves high levels of involvement with the academic dimension, but a more uncertain relationship with the social aspect. The pupil understands the means, but may not accept the ends of the social dimension, or he or she may accept the ends but does not have the means to realise them. King (1969) makes a similar separation within his research alluding to Goffman's (1961) distinction between an actor's performance of a role and the actor's disposition towards that role. This relationship can be more or less close or distant. A close relationship is called 'embracement', where the player embraces a role and is in turn embraced by it. 'Attachment', on the other hand, involves playing a role but not fully embracing it. It is, argues King (1969: 30), ‘a mechanism in allowing role-involvement without commitment to organisational goals.' 
In addition, Bernstein offers us three further variants. Deferment is when the pupil's involvement is suspended - 'watching the state of play' (Bernstein 1977: 45). This position is of only passing interest to us here - given the longitudinal and retrospective nature of our respondents' biographies and the temporary nature of deferment. Estrangement occurs when the pupil accepts the social and academic ends of the school, but does not understand how to realise these ends. Alienation is the most negative form of involvement with the school and involves a lack of understanding of the means and a rejection of the ends of both the academic and social dimensions.

In the following sections, we explore the biographies and orientations of our sample in relation to these four modes of involvement. We begin by examining the overall profile of the sample and then look in depth at the journeys to commitment, detachment, estrangement and alienation. Allocating individuals to analytical categories is never an exact science and some narratives displayed both detachment and estrangement, and estrangement and alienation. Additionally, it is clear that the level of involvement changed through the school career. Some, indeed the overwhelming majority, of our respondents started from a position of commitment which then shifted over the years. For the purposes of this study, the allocation of any particular individual is done on the basis of the dominant mode of involvement within their accounts. ${ }^{2}$

\section{THE PROFILE OF INVOLVEMENT}

\footnotetext{
${ }^{2}$ For more details on the attributes of the sample and their individual profiles, see the full report (Power et al 2009)
} 
The distribution of the dominant modes of involvement of our respondents is uneven (Table 3). Commitment and detachment are the most frequent modes of involvement. As with all samples requiring voluntary participation, there is likely to be some systematic bias in the response rate. It is probable that the pupils who recall their time at school in terms of estrangement and alienation are those least likely to have participated in the interviews.

\section{TABLE 3 GOES ABOUT HERE}

Although the numbers within the sample are far too small to ascertain any statistical relationships, Table 4 shows that there is certainly no straightforward relationship between the occupational background of a respondent's parents and their subsequent mode of involvement. For example, the majority of pupils from working class backgrounds displayed commitment to their old school. However, it is worth noting that no pupils from middle or intermediate class backgrounds became alienated or estranged from their schools - even if their involvement was more ambiguous and distant.

\section{TABLE 4 GOES ABOUT HERE}

It appears that there is a gender dimension to the mode of involvement (Table 5). While we have fewer female respondents overall ( 8 female compared to 15 male), three quarters of them fall within the 'committed' category. This may reflect some of the tensions between gender and academic ability that we have discussed elsewhere (Power et al 1998b)

\section{TABLE 5 GOES ABOUT HERE}


It should be noted that, while there is no necessary relationship between involvement and academic attainment with the more positive modes of involvement, there is inevitably a relationship between attainment and lack of involvement (Table 6). Only one from the five respondents estranged or alienated at school gained any post-school qualifications, and, in fact, this achievement was the result of returning to education to complete a vocational qualification and then transferring to a degree programme many years later.

\section{TABLE 6 GOES ABOUT HERE}

In the following sections, we explore some of the qualitative factors behind these variable modes of involvement.

\section{Commitment}

Eight of our respondents displayed commitment to their school when they reflected on their experiences. They came from homes with diverse occupational backgrounds and levels of educational inheritance. As already noted, there is a marked gender dimension, with the large majority $(6 / 8)$ being female. This is even more marked when one considers the under-representation of women within our sample (8/23).

Evidence of commitment is shown by the respondents' strong appreciation for all that the school had done for them. They reflected on their time at school as being one of happiness, e.g.: 
And I loved school, actually, I enjoyed it, I really loved it. [21]

I think the quality of education there was absolutely superb. [5]

A common feature in all these accounts was the strong preference of their parents for the school during the time they were making the transition to secondary education. To some extent, and unlike the pupils in King's grammar school who were allocated on the basis of passing the 11+ alone, all the parents of AP holders had to be proactive in trying to gain a place for their child at the preferred school. Some respondents, even those from working class homes, recalled receiving tutoring before the entrance test.

Our committed respondents spoke of strong support for the school from their parents after they had entered the school. Parents with higher levels of educational inheritance often enjoyed close connections with the school, e.g.:

Oh, she loved it...She just loved the fact that her daughter was there. [1]

There were also high levels of involvement in both the academic and social structures of the school. For example, all out schools had strong academic 'push' and our committed respondents all thrived under the pressure:

We all worked, you know, we all enjoyed it and wanted to achieve and were pushed to achieve. [21] 
I was a very intense studier and there's a very good environment to do that. [17]

Everyone from this group of respondents spoke warmly of the opportunities that their also school offered for non-academic development. Extra-curricular activities such as sport formed an important part of their school experience and helped to increase involvement. Many of our AP holders spoke of the problems created by not having enough money to participate in these activities, but our 'committed' pupils experienced this as less stigmatising than some of the others, e.g.:

I never had a problem with the fact that mum and dad couldn't afford the whole school fees apart from the trips...That was life. [21]

In general, it would appear that it is the ability to accept and realise the social, and not just the academic, ends of the school that distinguishes many of our female respondents from their male counterparts. The extent to which private schools are successful in wholly inspiring girls is also evident in Roker's (1993) research. In her interviews with AP holders, she notes how when 'faced with two quite different sets of behaviours... many pupils effectively chose to incorporate the new aspirations and values of the school into their existing values' (1993: 134). Whether boys' peer group cultures are more effective at resisting such incorporation or whether boys' schools are less effective at instilling the desired aspirations and values is difficult to determine. 
Certainly, our 'committed' pupils all developed strong friendships with their new schoolmates (some of which continue to this day) at the expense of friendships developed outside the school. Particularly for AP holders from middle class homes, the cultural gap between the school and the home was less marked than for others. While they may have suffered the disadvantage of low income, they fitted in in other ways, e.g.:.

I sounded as posh as the rest of them so that didn't distinguish me. [1]

The high levels of involvement with school activities and the close relations with peers within the school meant that relations with peers outside school were either significantly weakened or abandoned altogether. Some respondents spoke of the way in which their 'old' friends turned away from them when they started a different secondary school, e.g.:

They just perceived that you wouldn't want to be their friends anymore if you went to that school. [5]

I was kind of ostracised, I suppose, locally because I was always seen as the kid that went to the posh school. ...I didn't have any friends locally at all. [16]

Even when respondents wished to maintain friends inside and outside school, the school demands - such as extra-curricular activities, homework and time spent travelling often made that impossible. 
In terms of their destiny, all but one went on to higher education and all were in professional positions (excluding those taking 'time out' for childcare). These respondents look back on their schools, and the APS, as a positive legacy and a crucial element in their achievements, e.g.:

I felt very lucky and very privileged, then and now, even more so now as a parent, that I was given this fabulous opportunity. [16]

\section{Detachment}

Ten of our respondents exhibit a 'detached' involvement with their schools. They ascribed to the academic means of the school and realised, with varying degrees of success, the academic ends. However, they did not fully embrace the school - and in particular, appear to have distanced themselves from the social dimension of the school. As with our 'committed' respondents, our 'detached' respondents come from diverse backgrounds. It should be noted, though, that all but one are male.

These respondents appreciated their schools along the academic dimension, e.g.:

It was a good education...I got lots of opportunities there that I wouldn't have got, probably, at a local state school. [4]

However, alongside this appreciation, there was ambivalence about other aspects of their experience, e.g.: 
The whole emphasis of the school is around academic interest and, you know, conducting your life as an intellectual rather than as a more active person. [19]

There was often some regret about the extent to which academic success had been achieved at the expense of more social objectives, e.g.:

I believe that had I not gone to that particular school, if I'd have gone to one of the local schools, I wouldn't have achieved the same level of academic qualification ... but the social thing, from mixing with people, possibly slightly detrimental. [20]

The families of our 'detached' group of respondents were apparently happy for their children to attend these schools, but there seems to have been a less intense desire amongst these parents than amongst those of our 'committed' respondents for a place at the school. For example, one recalled:

I don't think there was any undue pressure from my parents. I think they were keen for me to do well but I think it was much more important for mum that I was happy. [2]

There is a sense in which the parents, like their children, appear to be slightly detached from the school. They watched the progress of their children without having a close involvement with the child's school, e.g.: 
I think as long as I was doing okay academically then they weren't really that fussed about other stuff. [4]

Like our 'committed' respondents, this group both understood the means and accepted the ends of the academic dimension of the school. They generally fell in line with the priorities of the school. However, they do not always recall their academic achievements with pride. Full commitment to the school was jeopardised if the pupil's position within ability groups declined, e.g.:

... suddenly I was plunged into an all boy environment and very high academic pressure...It ended up putting a lot of stress onto me and I didn't handle too well... ...I wasn't so happy in my school, my secondary school years. [2]

In general, these respondents' descriptions of their time at school are tinged with a sense of something lost. The strong emphasis within these schools on the academic dimension of success sometimes led to a marginalisation or rejection of the social dimension, as the following comment illustrates:

And actually, as I found, up until the A-levels it got worse and worse. Very unpleasant at times. When you experience that at the time it's quite horrific, when you look back on it I think you tend to dress it up as character building. ...And I think 
that's probably one of the downsides of the school: they're too narrow, too narrow with where they want to push people. [20]

\begin{abstract}
Alongside those respondents who rejected the social dimension of their school were those who appeared unable to become fully involved in the life of the school. This is particularly the case for pupils who were made to feel different, for example, through being singled out as being Jewish. Financial difficulties, particularly when combined with long journey times, also prevented pupils from participating fully in non-academic aspects of school life.
\end{abstract}

This group had much weaker friendship bonds within the school. Just as one of our 'committed' respondents remembers fitting in because her accent was as 'posh' as that of her classmates, working class respondents recall their accent being a barrier, e.g.:

I remember being, I don't know what the word is for it - teased, bullied - which one, for my accent, which to all intents and purposes is about your background as well. [11]

Amongst these 'detached' accounts, there is a strong sense of isolation:

It made me feel that I had more in common with my family and less in common with my school to be honest...I felt a bit of an outsider at school from the group of people that I was with. [2] 
Several pupils recall feeling stigmatised because they were poor:

"Not fitting in" is probably too strong a word. But I would say that there was a degree of "You're a poor kid", which some of the wealthier pupils would sort of choose to exploit by way of establishing themselves as more important members of school society. [19]

I always felt a little bit like the poor relation there if you know what I mean. Cos I think it's things like the school uniforms. ...You can buy the school uniform from Tesco or whatever or buy the proper school uniform from the school, which is like four times as expensive. So obviously, as we were, you know, fairly hard up, then I used get to get the Tesco bought one with the badge sewn on. It was just little things like that...and the fact that my dad used to quite often drop me off in his taxi, and I think that I was little bit, I don't know if I was embarrassed about it or whether I just felt a bit self-conscious about it. [6]

Very few of these 'detached' respondents have maintained contact with any of their old classmates. Neighbourhood rather than school friendships were much stronger.

In terms of their destinations, the educational and occupational profile of our 'detached' respondents is similar in many ways to that of our 'committed' group, reflecting the shared understanding of the means and acceptance of the ends of the academic 
dimension. All but one left school to take degrees and are in professional occupations. However, while detachment may not have any impact on level of occupational destination, it may affect orientations. There was significant ambivalence among many of them about the value of the kind of education their received. In addition, their lack of inschool networking may have led to a lack of potentially important social networks. On the other hand, detachment might protect one from the pain of estrangement experienced by our next group of respondents.

\section{Estrangement}

In many ways, estrangement is the opposite of detachment. Detachment arises when a pupil accepts and can realise the academic dimension, but distances themselves from the social aspects of the school - either because they feel they do not belong or because they reject the school's 'character-building' aspects. Estrangement, on the other hand, arises when one fully embraces the social and academic ends of the school but, for a variety of reasons, cannot realise these ends. Bernstein presumes that accepting the social ends of the school will automatically enable the pupils to realise them. However, our estranged pupils were not able to realise the academic or social ends of the school. It may be, as Bernstein argues, that they do not understand the means. Or, it may be that they are denied involvement.

Our two 'estranged' respondents are committed to the idea of the school, but their experience of academic failure made this a particularly painful position. Because they 
believed in the school, these respondents account for their failure in terms of their own choices and behaviour rather than any failure on the part of the school.

The relationship between the family and the school of our estranged group is mixed. For one of our respondents, there was huge investment on the part of her mother for her to get a place:

So she focused and focused on just education, education and private tuition and everything to get us to that school. I remember the day that the letter came through and my mum was so...she was so excited that we'd got a place, she was crying...She was crying because she'd bloody struggled so hard to get us into the school because it was like a major achievement. [10]

For the other, it was part of 'grooming' on the part of the primary school rather than any parental push and her mother had little involvement with the school while he was there.

Despite the initial commitment to the school, both of our respondents struggled with the academic side of their education. Achievements and confidence gained at primary school faded in the more competitive and academically-oriented push of their secondary schools, e.g.: 
I was going to do something wonderful, that everyone was going to be proud of. But it didn't turn out like that. Very quickly I knew I wasn't really capable of the doing the work that they demanded. [9]

Notwithstanding the desire to belong and their commitment to the school, neither of our 'estranged' respondents were able to participate fully in the social domain, and a significant part of this was that they did not feel, or perhaps were not encouraged to feel, that they 'fitted in' at the school. Neither of these respondents enjoyed close relationships with their peers at school. They were marked out as 'different' on a number of grounds. One of our 'estranged' respondents was black and from a single parent family:

I think at one point I made the mistake of telling someone my mum and dad weren't married and it was like a look of horror on someone's face. [10]

Our other 'estranged' respondent recalls the double stigma of not having two parents at home and being gay:

I was different somehow, I don't know how, you know. These guys had the money, had clothes, had a normal life and two parents, do these things that I'd never done and could see that I'd never be able to do. [9]

While these differences were important, the issue of financial disadvantage also recurs through these respondents' narratives, e.g.: 
I knew all these people around me were paying to go to this school. And I could see them in their perfect smart blazers, everything was very crisp and everything was perfect. And I felt very much that I wasn't. I did make a few friends, but I still felt very alone, very isolated. [9]

The estrangement experienced by these respondents was exacerbated by isolation from 'local' friends. Attendance at their 'posh' school created distance from their neighbourhood friends, particularly when combined with an aspirational parent:

Well, we didn't have much in common with them anyway because it was a council estate and we sort of felt we were better than a council estate. And we'd sort of grown up to think, you were raised to think, you were better than those on a council estate. [10]

I felt a bit distanced from local kids because obviously I went to the posh school...it wasn't a huge issue, but I did feel distanced from people who'd gone to, from my year at school. [9]

In terms of destination, both of our respondents in the 'estranged' group had very high occupational aspirations at the start of their secondary schooling. Moreover, they both had clear intentions to go to university and had even identified the university. In the event, one 
left school at 16 and twice dropped out of A level courses. The other completed her A levels (achieving two E grades) but then left full-time education.

\begin{abstract}
Alienation
Alienated pupils are those whose involvement with the school is one of disenchantment. Even if they start off being committed to the school, they cannot or will not realise the academic ends of the school, and ultimately reject the social dimension as well. All of the alienated respondents in our sample came from working class backgrounds. All are male.
\end{abstract}

The memories of this group of pupils are generally negative, e.g.:

The more and more I look back on it now I only remember a lot of the bad stuff. The not wanting to go to school, the trudging, getting dad to pick me up in his builder's van from the bottom of the road rather than come to the school. [14]

However, unlike the estranged respondents, they do not see this 'bad stuff' in terms of their own failure, but in terms of failings within the school.

These respondents recall ambivalence about going to the school in the first place - and the pressure seems to have come initially from their primary school rather than their parents: 
I felt pressurised to go. I was given this opportunity; my teachers at my primary school said "You've got to do it. You've got to take this opportunity". ... and I felt as if I had to go because everyone had said, "Don't miss this opportunity". [14]

Another recalls that his mother actually did not want him to go to the school as her own experience of grammar school had been negative. None of these respondents recall close involvement between their parents and their schools.

None of our three 'alienated' pupils ended up accepting the academic demands of the school. Even if they began their secondary school careers with commitment, they went on to reject its demands. Again, the contrast between their confidence at primary school and the loss of confidence on entering secondary school appears important.

Relations with teachers there were not positive and there was resistance to what was seen as the narrowness of the curriculum and the teaching style, e.g.:

I didn't think the teaching was very good. I thought there were some good teachers and there were some absolutely awful teachers. ...I'd have said probably three in ten teachers did it by means of bullying. I didn't react well to that, I rebelled against that. [7]

These three respondents did not particularly respect their teachers, and social class seems to have been an issue in this: 
I can probably count on one hand the ones that I had any respect for...but they were both working class. [14]

Sometimes a single incident could appear to shift a pupil from a more positive mode of involvement to alienation. One recalls how he missed a tournament when his mother's car broke down and was subsequently suspended from sport. He marks that as the beginning of his disillusionment:

It does all go back to completely being unfairly treated because a car breaks down. I'm sorry, we didn't drive round in Rolls Royces, we had a Datsun or a Nissan or whatever it was at the time. [7]

Class background was an important issue not just in terms of these respondents' orientation to the school, but also with regard to their relations with their classmates. These AP holders felt very much like 'poor relations':

There was a hierarchy at Bankside College. Boarders were top of the hierarchy, full paying boarders...then you came down to day-boys, they were pretty low as far as they were concerned, they were all [locals] and were scum. [14]

Some of these respondents were disdainful of their more affluent peers at school. There was often a sense that their teachers did not live in the 'real' world: 
I was going back to school and being told what to do by a group of young men who I wouldn't have given the time of day in real life. And they had gone through public school, university, straight back there. They'd never paid a bill in their life. ...I just had no respect for ninety-five percent of the people who were there. And the older I got the more I looked at the people who were around me at school and just thought, "No, you're not my type of people." [14]

Like our detached respondents, our alienated respondents all recall being much closer to their non-school friends whom they saw socially outside school hours. Far from pulling these boys away from their neighbourhoods and families, their experience of secondary school seems to have drawn them closer to their home, e.g.:

I was very much a Smalltown boy, much happier with the working class, struggling to be middle class ... I keep talking about Smalltown all the time. ...Smalltown personifies to me everything that I consider to be normal, rounded. [14]

These three still remain close to these non-school childhood friends to this day.

In terms of destinations, none of our 'alienated' respondents fulfilled the academic promise that one might have expected from them at the start of their secondary education. Only one went on to higher education and then dropped out after a year. Nevertheless, in terms of 
income, these three alienated respondents are relatively affluent. Their high earnings are a source of pride to them, e.g.:

I still maintain I am the son of a builder...I'd like to go back to Bankside to sit down with a lot of them and say, "What are you doing now? How much do you earn?" I guarantee you - I don't know anyone else my age who earns what I earn. [14]

Such comments suggest that even the financial success of these respondents cannot really be attributed to their involvement in the Scheme. .

\section{Conclusions and discussion}

This paper has attempted to unravel some of the processes that lie behind the variable performance of our AP holders. The sample, deliberately selected to include the more disadvantaged AP holders, has provided diverse accounts of their experiences of sponsorship, of stigma and of success.

Firstly, and as noted earlier, we emphasise that the relationship between socio-economic disadvantage and mode of involvement is not straightforward. Working class pupils with low levels of educational inheritance can be found in each category of involvement. Children from single parent families experienced different levels of involvement too. However, it is possible to identify some tendencies from within our (albeit small) sample. All of the pupils who came from homes where at least one parent was in a middle or intermediate class occupation accepted and realised the strong academic objectives of the 
school. They may have been more ambivalent about the social dimensions of their schools, but managed to distance themselves from these without jeopardising their academic progress to any serious degree. Over half our working class pupils $(6 / 10)$ were also able to accept and realise the academic objectives of the school, but a significant minority $(4 / 10)$ did not. This suggests that a non-manual class background protects children from estrangement and alienation, even where money is tight.

The difficulties of economic hardship were frequently mentioned. Virtually all spoke of the fact that they could not participate in the 'semi-formal' activities of the school curriculum, such as field-trips, cultural visits or foreign exchanges because their parents could not afford them. The lack of participation in weekend and after-school activities was compounded by the very long journeys to and from school which were commonly mentioned. Although many of their wealthier classmates would also have experienced long travelling times, the relative poverty of our AP holders meant they had a greater reliance on public transport. It is likely that this lack of participation in activities more associated with the social dimension of the school contributed to the relatively high levels of detachment within our sample.

However, while none of the respondents was 'well off', their relative financial hardship was not universally experienced by them as a source of stigma. For some it was simply a 'fact of life' which prevented them undertaking some activities but, for them, it was not a major issue. For others, feeling like the 'poor relation' was the defining characteristic of their time at school. It appears, from this small sample, that financial hardship combined 
with cultural discontinuity between the home and the school contributes to a sense of stigmatisation. For most of our students, this discontinuity took the form of social class differences. For a few, it stemmed from differences in race, religion and sexuality.

It is also worth noting that, while almost half of our respondents (11/23) came from single parent families, this was experienced as a source of stigma by only two students. Neither of these students came from middle or intermediate class homes, even though these accounted for the majority of single parent households in the sample (7/11). Again, this might suggest that a non-manual class background protects children from the potential stigmatisation of coming from a single parent family.

In addition, and relatedly, we need to comment on the gender aspect. Why is it that our committed respondents are largely female and our alienated respondents entirely male? Our sample is small and imbalanced in terms of the number of men and women interviewed. Nevertheless, the difference is striking. It may be that our girls' schools embodied the forms of 'academic feminism' identified by Arnot (2002), which underscored the importance of high academic attainment for competing with males. However, the greater levels of involvement of our female respondents arise not so much from their acceptance of the academic dimension of their school, but from the acceptance and realisation of the social objectives of the school. After all, our 'detached' category is comprised largely of male respondents. As mentioned earlier, it is unclear whether the more effective incorporation into the social dimension of the school arises from schoolgirl cultures, girls' school practices or a combination of both. Certainly the 
contrasting modes of involvement require further investigation in order to unravel the relative importance of contrasting peer-group cultures, school composition and the particular attributes of a school's social and academic dimensions.

What we have not been able to explore in any depth in this research is the extent to which school attributes and practices can reduce or increase this sense of stigmatisation and consequent lack of involvement. Although the schools were all prestigious and academically selective, they had different histories, different cultures and traditionally served different social groups. For example, the traditional public schools placed more emphasis on the social 'character-building' dimensions of schooling (see, Walford 1986). It is possible that within these schools it was more difficult for pupils to hold on to a position of detachment throughout their school career than it was at the day grammar schools.

We also have only sketchy data on how the internal organisation of the school might have affected our respondents' engagement with their schooling. Their accounts would give some support, though, to King's (1969) conclusion that, in highly stratified schools such as these, the place of the pupil within the school hierarchy is a very important factor in involvement. Indeed, he argues that, in the grammar school he studied, it was more important than home background. Certainly, within our small sample, being 'top' of the class promoted involvement even for working class pupils with low educational inheritance. On the other hand, losing position within the academic hierarchy, either on 
transfer from primary school or on progression through secondary school, jeopardised involvement.

\begin{abstract}
Although the Assisted Places Scheme has disappeared and may, or may not, return in a different guise, the enduring issues of the risks and benefits of sponsoring disadvantaged pupils and students into advantaged milieux will not. The experience of our AP holders shows that the legacy of such sponsorship - whether positive or negative - has a lasting effect on adult lives.
\end{abstract}




\section{REFERENCES}

Arnot, M. (2002) Reproducing Gender. London: RoutledgeFalmer.

Bernstein, B. (1977) Class, Codes and Control Vol 3. Second Edition, London: Routledge and Kegan Paul.

Bernstein, B. (1996) Pedagogy, Symbolic Control and Identity, London: Taylor \& Francis.

Douse, M. (1985) 'The background of assisted place scheme students', Educational Studies, 11 (3), 211-217.

Edwards, T., Fitz, J. and Whitty, G. (1989)The State and Private Education: An Evaluation of the Assisted Places Scheme. Basingstoke: Falmer Press.

Goffman, E. (1961) Encounters, Indianapolis, US: Bobs Merrill.

Jackson, B. \& Marsden, B. (1966) Education and the Working Class, Harmondsworth: Penguin.

King, R. (1969) Values and Involvement in a Grammar School, London: Routledge and Kegan Paul.

Power, S., Whitty, G., Edwards, T. and Wigfall, V. (1998b) 'Schoolboys and schoolwork: gender identification and academic achievement', International Journal of Inclusive Education 2 (2) 135-153.

Power, S., Whitty, G., Edwards, T. and Wigfall, V. (1998a) Schools, families and academically able students: contrasting modes of involvement in secondary education, British Journal of Sociology of Education, 19(2):157-75.

Power, S. Whitty, G. and Wisby, E. (2006b) The Educational and Career Trajectories of Assisted Place Holders, London: The Sutton Trust.

Power S, Whitty, G. and Edwards, T, (2006a) Success Sustained? A Follow-Up Study of the 'Destined for Success' Cohort', Research Papers in Education, 21, 3, pp 235-253, 2006.

Power, S.. Curtis, A., Whitty, G., Edwards, T. \& Exley, S. (2009) "Embers from the ashes"? The experience of being an assisted place holder. London: The Sutton Trust.

Roker, D. (1993) 'Gaining the edge: girls at a private school', in I. Bates and G.

Riseborough (eds) Youth and Inequality. Buckingham: Open University Press.

Walford, G. (1986) 'Ruling-class classification and framing', British Educational Research Journal, 21 (2), 183-195.

Walford, G. (1987) 'How independent is the independent sector?', Oxford Review of Education, 13 (3), 175-196. 